\title{
A formaçáo do terapeuta ocupacional e seu papel no Núcleo de Apoio à Saúde da Família - NASF do Recife, $\mathbf{P E}^{1}$
}

\author{
Andréia Carolina Santos de Lima ${ }^{a}$, Ilka Veras Falcão ${ }^{\mathrm{b}}$ \\ a'Universidade Federal de Pernambuco - UFPE, Jaboatão dos Guararapes, PE, Brasil \\ ${ }^{\mathrm{b}}$ Departamento de Terapia Ocupacional, \\ Universidade Federal de Pernambuco - UFPE Recife, PE, Brasil
}

\begin{abstract}
Resumo: O objetivo é identificar o papel e a formação de terapeutas ocupacionais atuantes no Núcleo de Apoio à Saúde da Família (NASF) do Recife, PE. Trata-se de pesquisa exploratória, de abordagem quantitativa, realizada em 2011 com dez terapeutas ocupacionais, sendo os dados obtidos mediante questionário autoaplicável. Para as entrevistadas, o papel do terapeuta ocupacional é oferecer atenção integral com enfoque no desempenho funcional, prevenção de incapacidades, reabilitação e inclusão social. Nos casos acompanhados, o apoio matricial é a mais frequente atuação do terapeuta ocupacional junto às equipes de saúde da família de referência. Os espaços comuns para intervenção são a Unidade de Saúde da Família e o domicílio dos usuários, sendo a pouca efetividade das políticas públicas a maior dificuldade referida pelas entrevistadas para o trabalho no NASF. A formação das terapeutas ocupacionais é generalista, mas para 70\% das entrevistadas não é suficiente para atuação no NASF; e, entre as que desejam receber formação, os temas apontados se referem à atenção primária, programas e políticas de Saúde. Conclui-se que o papel do terapeuta ocupacional no NASF do Recife é entendido por suas atribuições específicas no desempenho funcional e na prevenção de incapacidades, configurando-se o núcleo da profissão e a atenção integral à saúde das pessoas e à inclusão social como atuação conjunta com os demais profissionais no campo da atenção básica. A formação para as terapeutas ocupacionais entrevistadas mostrou-se insuficiente para a atuação no NASF, sendo essa uma nova área para atuação e atualização desse profissional.
\end{abstract}

Palavras-chave: Terapia Ocupacional, Saúde da Família, Atenção Primária à Saúde.

\section{The vocational training of occupational therapists and their role in the Family Health Support Center (NASF) in Recife, Pernambuco State}

\begin{abstract}
The objective of this study is to identify the role and training of occupational therapists in the Support Center for Family Health (NASF) in Recife, Pernambuco state. It is an exploratory research of quantitative approach performed with ten occupational therapists in 2011; data was obtained by self-administered questionnaires. According to the interviewees, the role of the occupational therapist is to offer holistic attention focused on functional performance, prevention of incapacities, rehabilitation, and social inclusion. Matrix support is the most common type of support provided by occupational therapists and Family Health teams to the monitored cases. The most commonly used places in these interventions are the homes of patients and the Family Health Center. The small effectiveness of public policies was mentioned as the greatest difficulty. In spite of the general character of the vocational training provided, it was considered insufficient for the NASF by $70 \%$ of the interviewees. The need for themes such as primary health care and health programs and policies was highlighted by those who wanted to be trained. We conclude that the role of the occupational therapist in the NASF is based on specific attributions in functional development and prevention of incapacities. The core of the profession, holistic health care, and social inclusion are considered attributions in common with those of primary health care workers. Vocational training as preparation for working in the NASF was considered insufficient by the interviewees, once it is a new area for professional acting and updating.
\end{abstract}

Keywords: Occupational Therapy, Family Health, Primary Health Care.

Autor para correspondência: Andréia Carolina Santos de Lima, Núcleo de Apoio à Saúde da Família, Unidade de Saúde da Família Maranguape II A, Rua 93, 61, CEP 53400-000, Paulista, PE, Brasil, e-mail: andreia.carolina@ gmail.com

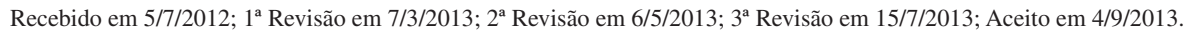




\section{Introdução}

Em 1978, durante a Conferência Internacional sobre Cuidados Primários de Saúde, foi elaborada a Declaração de Alma-Ata, expressando a necessidade urgente da promoção da saúde por parte de todos os governos. A conferência enfatizou que a meta mundial seria garantir condiçôes saudáveis para a população, o que requer uma relação intersetorial entre as políticas públicas, considerando a promoção e proteção da saúde como imprescindível para o desenvolvimento socioeconômico e para a melhor qualidade de vida e a paz mundial (DECLARAÇÁO..., 1978).

Associando-se aos intensos movimentos e às lutas pela democracia e melhoria das condiçôes de vida, contemporâneos à Reforma Sanitária e à ampliaçáo do conceito do ser saudável, as autoridades brasileiras se comprometeram com a meta aprovada em Alma-Ata (COSTA; MIRANDA, 2008-2009). Segundo o artigo $196^{\circ}$ da Constituição Federal Brasileira (BRASIL, 1988):

A saúde é direito de todos e dever do Estado, garantido mediante políticas sociais e econômicas que visem a redução do risco de doença e de outros agravos e o acesso universal e igualitário às ações e serviços para sua promoção, proteção e recuperação.

Apoiado nesse conceito ampliado e visando conferir o acesso universal e igualitário aos serviços e tendo como prioridade a atenção primária à saúde, o Sistema Único de Saúde (SUS) é assegurado como política de Estado pela Constituiçáo Brasileira, sendo regulamentado pela lei 8.080/90 - Lei Orgânica da Saúde (BRASIL, 1990a) - e pela lei 8.142/90, que dispõe sobre o controle social no SUS (BRASIL, 1990b). O SUS é criado num cenário que busca novos modelos assistenciais, trazendo a diversificaçáo dos serviços, a qualificação dos recursos humanos e mudanças na natureza do trabalho (COSTA; MIRANDA, 2008-2009).

O SUS tem por objetivos a promoção, prevenção e recuperação da saúde, com base nos princípios de universalidade, equidade e integralidade. Sua organização tem como diretrizes a descentralização, a hierarquização, a regionalização, a participação social e a complementaridade pelo setor privado (BRASIL, 1990a).

Em um cenário de desafios para atender aos objetivos propostos tanto na Declaraçáo de AlmaAlta quanto na Reforma Sanitária, o Ministério da Saúde implanta em 1994 o Programa de Saúde da Família (PSF), tendo como meta a reorganização e a reestruturação da atenção básica (NASCIMENTO;
OLIVEIRA, 2010). O PSF, por meio de açóes de promoção, prevenção e recuperação da saúde, é um recurso para melhor alcançar a integralidade e resolubilidade do SUS (SILVA; TRAD, 2004-2005; NASCIMENTO; OLIVEIRA, 2010).

A partir dos anos 2000, o PSF se expande e se consolida nacionalmente, assumindo a denominação de Estratégia de Saúde da Família (ESF) e a função de ser a porta de entrada da rede e de reorientar o modelo brasileiro de atenção à Saúde (BRASIL, 2006). As açóes estão sob a responsabilidade da Equipe de Saúde da Família (EqSF), formada, pelo menos, por um médico de família ou generalista, um enfermeiro, um auxiliar de enfermagem e até 12 Agentes Comunitários de Saúde (ACS) (KELL; SHIMIZU, 2010). Se ampliada, a equipe conta ainda com profissionais de saúde bucal e de outras profissóes, de acordo com as definiçôes locais (BRASIL, 2011).

A ESF operacionaliza-se através do trabalho em equipe, responsável por famílias em um território adstrito, da formaçáo de vínculo e da responsabilização entre profissionais e populaçáo, apontando para um reordenamento do modelo de atençáo e das práticas em saúde (COSTA; MIRANDA, 2008-2009). Também a integralidade e a interdisciplinaridade como princípios e diretrizes do SUS e das políticas que respaldam o trabalho da Estratégia de Saúde da Família (BRASIL, 2009) requerem a ação de outros profissionais em conjunto com a equipe de referência, configurando-se o apoio matricial como um novo arranjo organizacional do trabalho. Nesse sentido a Equipe de Saúde da Família assume a responsabilidade integral pelo usuário e, quando necessário, busca em outro serviço ou equipe especializada, chamada de apoio matricial, a complementação de conhecimentos e formas de cuidado (BRASIL, 2004b; 2006; NASCIMENTO; OLIVEIRA, 2010).

O apoio matricial como ferramenta da humanização considera a singularidade das necessidades de saúde dos sujeitos e a responsabilização da Equipe de Saúde da Família pelo cuidado. A concepção de apoio matricial é oferecer a retaguarda assistencial ou técnica pedagógica, funcionando como uma metodologia para diminuir a fragmentação do sistema de saúde e ampliar a interdisciplinaridade, porque favorece a comunicaçáo entre os profissionais e os serviços (BRASIL, 2004a; CAMPOS; DOMITTI, 2007).

As experiências com o apoio matricial foram vivenciadas no Brasil, com a reforma do modelo assistencial e o fim dos hospitais de internação psiquiátrica e nos serviços de atenção básica, 
especialmente em Campinas, SP, e, a partir daí, surgem experiências em outras cidades e em propostas de programas do Ministério da Saúde como o Humaniza-Sus (BRASIL, 2004b), nas quais o apoio matricial é uma das ferramentas de organização e desenvolvimento do processo de trabalho (CAMPOS; DOMITTI, 2007; FIGUEIREDO; ONOCKO, 2008; DIMENSTEIN et al., 2009; BRASIL, 2009; CAMPOS; GUERREIRO, 2010; CUNHA;CAMPOS; 2011).

Seguindo nessa lógica de expandir a resolubilidade e humanizar o cuidado na atenção básica, o NASF é criado em 2008 como estratégia potencial de fortalecimento da ESF, ampliando sua abrangência e a diversidade de açóes e, consequentemente, sua eficácia e eficiência, atuando em conjunto com as equipes das unidades de saúde da família e sob a responsabilidade delas, compartilhando e apoiando as práticas no território (BRASIL, 2008a; BARBOSA et al., 2010).

Um marco importante para demarcação do espaço do NASF no âmbito da atenção básica foi consolidado na nova Política Nacional de Atençáo Básica, que ao reafirmar o seu papel de organizador das açóes de saúde, ressaltou a multi e interdisciplinaridade e o compartilhamento de açóes essenciais aos profissionais da ESF como também do NASF (BRASIL, 2011). A equipe do NASF é essencialmente multidisciplinar. Entre as diferentes profissóes que integram essa equipe encontram-se fisioterapeutas, terapeutas ocupacionais, médicos, profissionais de educação física, nutricionistas, farmacêuticos, assistentes sociais, fonoaudiólogos e psicólogos, conforme as necessidades particulares de saúde, vulnerabilidade socioeconômica e perfil epidemiológico de cada regiáo de abrangência (NASCIMENTO; OLIVEIRA, 2010).

Com vistas a revigorar as diretrizes de interdisciplinaridade, intersetorialidade, conhecimento de território, integralidade, controle e participação social, educação permanente em saúde, promoção da saúde e humanização, o NASF vem desenvolvendo açóes que contemplam o coletivo, que se propóem a superar a lógica fragmentada de atenção à saúde para a construção de redes de atenção e cuidado, colaborando para o alcance da integralidade (MÂNGIA; LANCMAN, 2008; BRASIL, 2009; BEZERRA, et al, 2010; MENEZES, 2011; MOLINI-AVEJONAS; MENDES; DE LA HIGUERA AMATO, 2010).

A operacionalização dos NASF deve priorizar o atendimento compartilhado e interdisciplinar, com troca de saberes, capacitação e corresponsabilização, utilizando como recursos estudos, discussão de casos e situaçóes, projetos terapêuticos, orientaçóes e atendimentos em conjunto, englobando apoio técnico-pedagógico e/ou assistencial (BRASIL, 2009).

O processo de trabalho do NASF depende de ferramentas que se articulam com os dispositivos propostos pela Política Nacional de Humanização, como a Clínica Ampliada, o Apoio Matricial, o Projeto Terapêutico Singular (PTS), o Projeto de Saúde no Território e a Pactuação de Apoio. A estratégia essencial dentro da lógica do NASF é a criação de uma rede de cuidados (BRASIL, 2004a; 2009).

Em 2009, um ano após a sua criação, o Brasil contava com 648 NASF, o que representou um avanço importante na atenção básica, à medida que significam novas formas de melhor cuidado à população (MOLINI-AVEJONAS; MENDES; DE LA HIGUERA AMATO, 2010; BEZERRA et al, 2010; MENEZES, 2011). Do mesmo modo que, nos últimos 20 anos, a implantação da ESF ocorreu paulinamente e com crescimento bastante variável, assim também parece ser a trajetória do NASF.

Verificando-se como esse processo ocorreu na cidade do Recife, PE, encontra-se que em 2001 a cobertura populacional era de 5,02\%, com 27 equipes, e que em 2010 a cobertura atingiu 54\%, com 255 equipes. O Plano Municipal de Saúde do Recife 2010-2013 define como meta atingir a cobertura de $70 \%$ até 2013 , estando um pouco além de 60\% em 2012 (RECIFE, 2010).

Quanto às equipes NASF, a Secretaria de Saúde do Recife implantou até junho de 2010 14 equipes, distribuídas por quatro dos seus seis Distritos Sanitários (Distritos Sanitários I, III, IV e VI), chegando no ano seguinte a 20 equipes NASF em todo o território. As equipes NASF do Recife são compostas por psicólogo, assistente social, farmacêutico, fisioterapeuta, fonoaudiólogo, nutricionista e terapeuta ocupacional (RECIFE, 2011).

Como evidenciado, são recentes e inovadoras as diretrizes para o apoio matricial e a implantação do cuidado integral e interdisciplinar. Sendo assim, é natural que os profissionais de Saúde chamados a ocupar esse lugar apresentem dificuldades para atuarem como apoiadores, o que pode ser verificado até mesmo entre equipes de saúde mental do município de Campinas, onde se iniciou essa construção, a partir da década de 1990 (BALLARIN; BLANES; FERIGATO, 2012).

A dificuldade na formação dos profissionais começa dentro das universidades, que insistem numa formação de profissionais de Saúde com 
direcionamento diferente daquele que a política pública de saúde demanda, dificultando a atuaçáo deles nesse sistema de saúde (ANDRADE et al., 2012).

Especificamente no caso do terapeuta ocupacional, o que rege sua formação são as Diretrizes Curriculares Nacionais do Curso (DCN) de Graduação em Terapia Ocupacional, que dispóem sobre a intenção de formar um profissional apto para o exercício das atividades gerais e específicas. As DCN do curso ainda consideram em seu projeto de formação o perfil sócio-epidemiológico e os principais agravos e condiçôes de vida e saúde, preparando o futuro profissional para uma atuação ampla, como destacado no inciso VI do artigo quinto, que cita como uma das habilidades

[...] inserir-se profissionalmente nos diversos níveis de atençáo à saúde, atuando em programas de promoção, prevenção, proteção e recuperação da saúde, assim como em programas de promoção e inclusão social, educação e reabilitação (BRASIL, 2002, p. 2).

Essas habilidades fazem parte das que são exigidas como competências de todos os profissionais que integram a equipe NASF (BRASIL, 2008a). No entanto, questionamos se a formaçáo do terapeuta ocupacional vem cumprindo realmente esse papel e como está se dando a inserçấo desse profissional nos NASF, em nossa realidade.

Assim, considerando o caráter recente da implantaçáo dos NASF do Recife, este estudo visa identificar o papel e a formação do terapeuta ocupacional inserido nesse campo de trabalho nessa cidade. Os resultados poderão ser utilizados tanto no âmbito acadêmico, para contribuir no processo de formação, quanto no profissional, para a educação permanente desses profissionais e a consolidação do serviço na rede de saúde do Recife.

\section{Material e método}

Pesquisa quantitativa, do tipo exploratória e de corte transversal com vistas a uma maior aproximação do tema em estudo (ANDRADE, 2004). O campo da pesquisa correspondeu aos NASF implantados na cidade do Recife até abril de 2011, cujas equipes dispunham de um terapeuta ocupacional, conforme listagem disponibilizada pela Diretoria Geral de Atenção a Saúde (DGAS) da Secretaria de Saúde da Prefeitura do Recife. Do total de 13 terapeutas ocupacionais constantes nessa listagem, três não responderam aos contatos, não devolveram o questionário respondido ou não foram localizados, sendo validados dez profissionais como sujeitos do estudo, os quais aceitaram participar da pesquisa assinando o Termo de Consentimento Livre e Esclarecido (TCLE).

O projeto de pesquisa foi autorizado pelo Comitê de Ética em Pesquisa do Hospital Otávio de Freitas, conforme identificador n. 0004.0.344.000-11. Os dados foram coletados em conjunto com duas outras pesquisadoras, utilizando-se um questionário semiestruturado, autoaplicável, construído a partir dos achados bibliográficos e correspondentes ao objetivo do estudo. O instrumento de pesquisa foi entregue pelas pesquisadoras, tendo sido todos devolvidos pelos sujeitos participantes em encontros presenciais ou via e-mail. Entre a entrega e a devolução dos questionários houve um intervalo de 30 dias e, náo se tendo resposta nesse prazo e ao final de três tentativas de contato, o sujeito foi excluído do estudo.

Para subsidiar todas as etapas do projeto foi realizado um levantamento bibliográfico na BIREME (Centro Latino Americano e do Caribe de Informação em Ciências da Saúde), em língua portuguesa, considerando publicações no período de 2001 a 2011 e, ainda, no site do Ministério da Saúde, sem limite de tempo, a partir dos descritores: Sistema Único de Saúde, Política de Saúde, Terapia Ocupacional, terapeuta ocupacional, Atenção Primária à Saúde, Saúde da Família, Apoio matricial, Clínica ampliada, Núcleo de Apoio à Saúde da Família (NASF), Equipe de Assistência, Recursos humanos, Profissional de Saúde, Formação profissional. As buscas foram feitas com termos unitários e depois associados à Terapia Ocupacional, formação profissional e NASF, visando refinar a pesquisa e aproximar-se dos objetivos de estudo.

Os descritores, quando associados, resultavam em menor número de artigos, que eram lidos e fichados; já do material bibliográfico oriundo da pesquisa com termos isolados, por ser mais volumoso, inicialmente foram lidos os resumos, que orientavam a seleçâo como adequada ou náo e, posteriormente, o artigo na íntegra, para a sua categorização conforme os temas em estudo e os achados da pesquisa de campo. Foram excluídas as publicaçóes que se repetiam e as que não se relacionam aos objetivos do estudo.

Para análise dos dados coletados a partir dos questionários foi organizado um banco de dados e considerada a frequência simples das respostas, utilizando-se para isso o programa Excel. Por fim, fez-se a correlação teórica dos achados com os conceitos e experiências disponíveis nas publicações selecionadas e, ainda, com os documentos do Ministério da Saúde e as Diretrizes Curriculares Nacionais de Cursos de Graduação. 


\section{Resultados}

Em relação à caracterização da população estudada, $100 \%$ eram do sexo feminino, estando $50 \%$ na faixa etária entre 27 e 29 anos e 50\% entre 32 e 36 anos; $40 \%$ eram casadas, $50 \%$, solteiras e $10 \%$ declararam outro estado civil. Todas são graduadas pela Universidade Federal de Pernambuco (UFPE), sendo metade com dois a quatro anos de formada $e$ as demais com oito a dez anos.

O papel do terapeuta ocupacional, segundo a opinião das integrantes da amostra, consta na Tabela 1. Vale salientar que era possível mais de uma resposta para cada questão.

No tocante à interação com outros profissionais, as terapeutas ocupacionais reconhecem existir uma ação interprofissional, a partir da discussão de casos, consulta compartilhada e acolhimento e, para a maioria, mediante assistência técnico-pedagógica.

Com relação aos profissionais que integram as equipes do NASF no Recife, segundo as entrevistadas, destacam-se as presenças do terapeuta ocupacional, do assistente social e do psicólogo em $100 \%$ delas. O farmacêutico está presente em $80 \%$, o nutricionista, em $70 \%$, o fonoaudiólogo, em $60 \%$, o médico e o fisioterapeuta, em $20 \%$ das equipes.

Os terapeutas ocupacionais e os demais membros da equipe NASF desenvolvem em corresponsabilização as açôes no território de abrangência. A ação mais citada foi a visita domiciliar (80\%), seguida dos grupos de educação em saúde (70\%). Foram ainda citados a consulta compartilhada (60\%); outras açóes em sala de espera, articulação com equipamentos sociais, encaminhamentos, escuta qualificada (60\%); o apoio matricial (50\%); e PTS (40\%).

Essas açôes são operacionalizadas em espaços no território de abrangência, sendo a Unidade de Saúde da Família e os domicílios citados por todas as participantes. Outra unidade de saúde, espaços administrativos e espaços de equipamentos sociais ou cedidos pelos centros comunitários também foram referidos como espaços para a atuação da equipe Nasf.

Os terapeutas ocupacionais na equipe NASF interagem com outros setores. Os mais citados foram: Educação e Assistência Social (90\%), Segurança (30\%); e Organizações Não Governamentais (10\%).

Sendo o NASF uma equipe de retaguarda para as equipes de saúde da família, pôde-se constatar que o apoio do terapeuta ocupacional a essas equipes se dá por meio de: matriciamento evidenciado na articulação entre as unidades de saúde e as unidades de referência ou com os outros setores; educação permanente; construção do Projeto Terapêutico Singular, conforme exposto na Tabela 2.

As principais dificuldades encontradas pelos terapeutas ocupacionais da equipe NASF para operacionalizarem suas açóes no território são: a carência na formação; as limitaçóes por parte do usuário, que não compreende a intervenção/ orientação, ou não a aceita; as dificuldades estruturais, como falta de recursos e de espaço ou de adequação deles para a realização das atividades; a falta de efetividade das políticas de saúde; e o desconhecimento do objeto de estudo da Terapia

Tabela 1. Papel do terapeuta ocupacional na equipe do NASF Recife.

\begin{tabular}{lc}
\multicolumn{1}{c}{ Papel do terapeuta ocupacional } & Frequência \\
\hline Atenção à saúde visando a integralidade do sujeito (reabilitação, funcionalidade) & 7 \\
Promoção da saúde e prevenção de doenças e incapacidades & 3 \\
Usuários e profissionais conhecerem a profissão e o trabalho do terapeuta ocupacional através & 3 \\
da prática e além do campo da saúde mental (divulgação da profissão) & 3 \\
Avaliar e tratar áreas e contextos de desempenho/atividade promotora de saúde & 2 \\
Sensibilização das equipes para o cuidado ao usuário com transtorno mental/reintegração social & 2 \\
\hline
\end{tabular}

Tabela 2. Apoio do terapeuta ocupacional à equipe de referência da ESF.

\begin{tabular}{|c|c|c|}
\hline Modalidade de apoio & Frequência & $\%$ \\
\hline Matriciamento & 8 & 80 \\
\hline Construção do PTS & 7 & 70 \\
\hline Educação permanente & 2 & 20 \\
\hline Articulação com unidades de saúde e de referência/outros setores & 2 & 20 \\
\hline Condução e gerenciamento do caso no território & 1 & 10 \\
\hline
\end{tabular}


Ocupacional, estando a maioria das respostas concentradas nas três últimas.

Quanto à opinião dos componentes da amostra acerca da formação oferecida pelo Curso de Graduação em Terapia Ocupacional, 80\% consideram que é generalista, justificando o embasamento teórico apesar da carência na parte prática, e afirmam que foram transmitidos conhecimentos em várias áreas de intervenção e formas de atuação. Para metade da amostra (50\%), o curso não enfoca nenhuma área específica; $20 \%$ das entrevistadas referem que o enfoque é dirigido para a Neurologia; $20 \%$, para a Saúde Mental; apenas uma entrevistada indicou $\mathrm{a}$ área de Terapia Ocupacional Hospitalar.

No que se refere à formação para atuar na atenção básica, 30\% das entrevistadas consideram que a formação recebida durante a graduação foi suficiente para sua atuação na equipe NASF, justificando que as disciplinas ajudaram, mesmo náo enfocando a atenção básica, e que essa atuação, por ser nova, exige atualização do profissional. Já para $70 \%$ das entrevistadas os ensinamentos transmitidos na graduação não foram suficientes para o trabalho do terapeuta ocupacional na equipe NASF, justificando a ssertiva pela falta de vivência prática.

No que concerne à pós-graduação das terapeutas ocupacionais, $90 \%$ possuem algum título de pós-graduação e afirmam haver relação entre a pós-graduação realizada e seu atual trabalho na equipe NASF. Nenhuma delas afirmou ter concluído outra graduação; no entanto, $80 \%$ das entrevistadas afirmaram que gostariam de receber mais alguma formação, para uma atuação profissional mais eficaz.

Dentre as terapeutas ocupacionais que têm interesse em aprofundar sua formação dirigida a esse campo, pouco mais de $50 \%$ informaram sua preferência por cursos que abordam temas da atenção básica, programas e políticas de saúde; 20\% desejam realizar um curso de pós-graduação mas não especificaram em que área e as demais apontaram temas específicos da profissão ou de saúde mental.

\section{Discussão}

A população estudada caracteriza-se por ser toda do sexo feminino, o que corresponde aos dados nacionais expostos no estudo de Haddad et al. (2010) em relação às categorias da Saúde. No atinente à faixa etária, todas as profissionais são jovens (faixa etária de 27 a 36 anos), com pouco tempo de formadas, variando entre dois e dez anos, condição semelhante à referida por Ambrósio et al. (2009).
O achado de que todas as terapeutas ocupacionais são graduadas pela UFPE está provavelmente associado ao fato de que esse curso é o mais antigo em funcionamento na cidade e o que mais forma profissionais regularmente. $\mathrm{O}$ curso oferecido por outra instituição de ensino superior lança no mercado de trabalho, a cada ano, um número reduzido de profissionais em relação ao curso da UFPE (VIEIRA, 2010).

As terapeutas ocupacionais avaliam que seu papel na equipe NASF relaciona-se à atenção integral à saúde dos sujeitos; ao enfoque no desempenho funcional, prevenção de incapacidades, reabilitação e integração social; atuação em saúde mental; e até divulgação da profissão. Verifica-se que os papéis reconhecidos contemplam os fundamentos $\mathrm{da}$ profissão previstos nas Diretrizes Curriculares do Curso de Terapia Ocupacional (BRASIL, 2002) e estão de acordo com Hagedorn (1999) e Barbosa et al. (2010), segundo os quais a Terapia Ocupacional busca o melhor desempenho funcional com o máximo de capacidade funcional. Essa especificidade da intervençấo e do conhecimento pode ser remetida ao núcleo, como o que é próprio da identidade de cada prática profissional (CAMPOS, 2000).

Outros papéis atribuídos a esse profissional fazem referência à atribuição em comum com as demais especialidades, o que configura o campo, conforme o autor citado, e também é previsto na portaria n. 154/2008 (BRASIL, 2008a). Essa concepção foi também encontrada num estudo realizado com fisioterapeutas de uma equipe NASF em Minas Gerais (BARBOSA et al., 2010).

Observou-se que, em cada equipe NASF, os terapeutas ocupacionais podem interagir com profissionais das mais diversas especialidades da Saúde, em suas ações no território de abrangência, ou seja, a equipe do NASF-Recife está composta considerando as possibilidades indicadas na portaria n. 154/2008 (BRASIL, 2008a), aumentando as possibilidades de oferecer-se um atendimento integral e da realização de açóes em conjunto, mais abrangentes e mais efetivas, junto aos casos que envolvem vários aspectos ou que anteriormente não eram assistidos (JARDIM et al., 2008; CAMPOS; GUERREIRO, 2010; MENEZES, 2011).

Chama a atenção o fato de terapeutas ocupacionais, assistentes sociais e psicólogos integrarem todas as equipes NASF, o que pode indicar uma opção da gestão municipal do Recife em priorizar profissionais da área de Saúde Mental, uma vez que as equipes de saúde da família se deparam cotidianamente com essa realidade (BRASIL, 2008a; JARDIM et al., 2008). Tendo em vista que a Terapia Ocupacional tem uma 
forte relação com a Saúde Mental, os terapeutas ocupacionais se envolvem com propriedade nesse meio, em que se concentram mais profissionais, e têm sua atuação mais reconhecida nas equipes NASF (DRUMMOND, 2007; SOARES, 2007; BEIRÃO; ALVES, 2010).

Além de interagirem com outras especialidades da Saúde, os terapeutas ocupacionais relatam que as açôes em sua equipe ocorrem intersetorialmente, com a Segurança, a Educação, a Assistência Social e com ONGs. A ação intersetorial surge como possível soluçáo para os gestores diante do desafio de buscar soluçôes integradas para questóes sociais complexas, possibilitando articular diferentes saberes e experiências e potencializar recursos humanos e financeiros (MALTA et al., 2009).

Apesar de ser reconhecida a sua importância e viabilidade nas políticas sociais, há limitaçôes que dificultam a sua implantação, pois, para isso, o modelo hegemônico, no qual cada setor torna-se o próprio objeto de sua existência, operando a própria reafirmaçáo do setor, precisa ser superado. Romper com isso significa mudar de paradigma, o que não é algo simples de ser alterado. A intersetorialidade precisa se construir em um novo espaço, baseado nas questóes concretas e complexas da realidade, para contribuir no enfretamento da questão (BONALUME, 2011).

Os docentes de Terapia Ocupacional percebem isso quando afirmam que a profissão tem ênfase na Política Pública de Saúde e pouca participação nas políticas de Educação e de Assistência Social, retratando a escassez de experiências para construir a intersetorialidade ainda na graduação (LOPES et al., 2008). O modelo de formação prima pelas perspectivas técnicas de cada profissão, em detrimento do incentivo ao trabalho em equipe com outras áreas. No entanto, no campo da Saúde como um todo, sempre haverá a necessidade de trabalho por meio da articulação com outras profissôes (ANDRADE et al., 2012). Sendo assim, faz-se necessário também atentar para e debater o planejamento e a mobilidade urbana, bem como a desigualdade e a falta de equidade no acesso aos espaços públicos saudáveis (MALTA et al., 2009).

Dentre as açôes em que o terapeuta ocupacional atua em parceria com outro profissional da equipe podem ser mencionadas as discussóes de caso, a consulta compartilhada, o acolhimento e a assistência técnico-pedagógica, essa última a mais citada por aqueles profissionais.

Vale ressaltar que os terapeutas ocupacionais que compõem as equipes no Recife, de acordo com as diretrizes do NASF, trabalham em conjunto com as equipes de saúde da família, priorizando as intervençôes interdisciplinares. Nessas equipes, a ênfase é dirigida às discussóes de caso, ao PTS, às intervençôes em conjunto e à corresponsabilizaçáo pelos casos. Os terapeutas ocupacionais também são responsáveis por açôes no território, em comum com as equipes de saúde da família, realizando trabalhos educativos, apoiando os grupos, os trabalhos de inclusão social e o enfrentamento da violência junto a equipamentos sociais (BRASIL, 2008a).

Cada ambiente proporciona um diferente contexto ao qual irão se adequar as decisóes do profissional e no qual irá se mostrar um diferente desempenho do usuário (MATTHEWS; TIPTON-BURTON, 2004). A metodologia da Reabilitação Baseada na Comunidade (RBC), por exemplo, precisa ser adaptada à realidade das diferentes localidades, respeitando suas necessidades e suas características (OLIVER; ALMEIDA, 2007). Por analogia, essa condição pode ser aplicada aos NASF.

Para atuar no território, os terapeutas ocupacionais e suas equipes utilizam como contextos de tratamento os espaços localizados no território de abrangência. A USF e os domicílios sáo os principais locais de trabalho desses profissionais, que atuam ainda em outras unidades de saúde, diferentes daquelas às quais são vinculados, em espaços administrativos dentro do Distrito Sanitário de origem, em espaços de equipamentos sociais e em espaços cedidos pelos centros comunitários.

O domicílio do usuário, sendo o local real onde são realizadas as suas atividades, configura-se como um local potencial para obter resultados bem-sucedidos e funcionais, uma vez que é o mesmo contexto em que se encontram os fatores e condiçóes reais do usuário e no qual deve ser exercido o seu desempenho ocupacional (MATTHEWS; TIPTON-BURTON, 2004).

O domicílio, como parte do contexto do usuário e também do grupo de determinantes sociais de saúde (BUSS; PELLEGRINO FILHO, 2007), configura-se como uma parte a ser considerada na prática da clínica ampliada, que tem como objeto de trabalho, além das doenças, os problemas de saúde, ou seja, condiçốes que ampliam a vulnerabilidade ou situação de risco e, ainda mais importante, o destaque ao indivíduo que materializa a doença e essas outras condiçôes (CAMPOS; AMARAL, 2007).

Como se vê em outras publicaçóes, o terapeuta ocupacional inserido na atenção básica faz uso de ambientes que não são restritos ao serviço de saúde, considerando as múltiplas potencialidades da comunidade para, assim, nesse espaço ampliado, 
realizar as suas açóes (JARDIM et al., 2008). Para dar vida às suas açóes no território, os terapeutas ocupacionais precisam relacionar-se também com pessoas da comunidade, formando vínculos e estabelecendo relaçôes de confiança para conseguir espaços onde possam atuar.

Os problemas estruturais, a falta de efetividade das políticas de saúde e o desconhecimento do objeto de estudo da Terapia Ocupacional foram as dificuldades mais citadas pelos participantes dentre as principais para a operacionalização das açôes. A falta de espaço adequado e a insuficiência de recursos também foram muito citadas, em concordância com os achados de Jardim et al. (2008).

Destaca-se ainda a carência de conteúdos específicos na formação do terapeuta ocupacional como uma das dificuldades para atuar na equipe NASF e na atenção básica. Nascimento e Oliveira (2010) identificam o conhecimento sobre as políticas de Saúde Pública, o território, o perfil epidemiológico e a rede de cuidados como necessários para a atuação nesse campo.

Por serem os sujeitos da pesquisa formados por uma mesma instituição de ensino superior, há um consenso da maioria em reconhecer a formação recebida como generalista e pouco direcionada a uma área específica. As Diretrizes Curriculares Nacionais preconizam que o egresso do Curso de Terapia Ocupacional tenha formação generalista e seja capacitado para o exercício da profissão em todas as suas dimensões (BRASIL, 2002). No entanto, o mesmo público reconhece a carência na formação em áreas diversificadas de prática profissional.

No que se refere à formação para o trabalho na atençáo básica/NASF, para 70\% das entrevistadas a formação não foi suficiente para atuar na equipe NASF, sendo carente de vivência prática. Isso pode estar relacionado ao fato de que o trabalho formal do terapeuta ocupacional no NASF, na cidade do Recife, é um espaço recente e os cursos de graduação não têm conseguido se ajustar rapidamente às novas demandas do mercado de trabalho. No caso da UFPE, o Curso de Terapia Ocupacional mantinha, até 2010, o mesmo perfil curricular implantado nos anos 1990, no qual a vivência prática em situações semelhantes às da atenção básica acontecia de forma descontinuada em projetos de extensão comunitária (UNIVERSIDADE..., 2010).

Conforme apontam Nascimento e Oliveira (2010), a formação dos profissionais de Saúde ainda é guiada pelo modelo biomédico. Essa formação não atende às solicitaçóes do SUS nem da atenção básica, deixando a desejar no que concerne à formação de vínculo, ao acolhimento, à escuta e até ao trabalho em equipe, à medida que se mantém distante dos serviços de saúde no período inicial da formação.

Todas que concluíram alguma pós-graduação afirmaram que o curso realizado tem relação com seu trabalho na equipe NASF, mesmo que indiretamente, o que se percebe nas profissionais que citaram a Pós-graduação em Psicomotricidade Relacional. Desse modo, nota-se que a pós-graduação representa uma possibilidade de complementação da formaçáo e está associada ao desejo de aprofundar a formação para atuar no NASF, em cursos abordando temas específicos da atenção básica, programas e políticas de saúde, abordagens específicas ou em Saúde Mental.

O Ministério da Saúde, como órgão gestor federal, é o responsável pelo desenvolvimento dos trabalhadores da Saúde, sua distribuição, regulação e gestão e ainda pela formulação de políticas orientadoras da formaçáo, conforme consta na Constituição Federal, artigo $200^{\circ}$, inciso III, que assegura os recursos financeiros para essa formação e define o perfil profissional adequado às necessidades locais (BRASIL, 1988). Possivelmente, como forma de cumprir esse papel, com algumas açóes conjuntas com o Ministério da Educaçáo e apoio de Secretarias de Saúde de estados e municípios, vêm sendo incentivados programas de qualificação, de formação e pós-graduação de profissionais de Saúde.

Nesse sentido, a Residência Multiprofissional em Saúde da Família tem sido uma estratégia positiva para formar profissionais com perfil para trabalhar no NASF, uma vez que é centrada na formação em serviço e fundamentada na interdisciplinaridade, tida como facilitadora da construção do conceito mais amplo de Saúde (NASCIMENTO; OLIVEIRA, 2010).

Além da residência, o Pró-Saúde e o Programa de Educação pelo Trabalho em Saúde (Pet-Saúde) também auxiliam a mudança na formação dos profissionais de Saúde, reunindo universidades e trabalhadores de Saúde, incentivando a integração dos cursos e criando experiências e vivências do agir em Saúde a partir da aproximação dos estudantes com a rede de atençáo básica através do ensino, pesquisa e extensão (FACUNDES et al., 2010). Um dos resultados esperados desse programa é o desenvolvimento de novas práticas de atenção e de experiências pedagógicas, colaborando para a reorientação da formação e para a implementaçáo das Diretrizes Curriculares Nacionais dos cursos de graduação da área da Saúde (BRASIL, 2008b). Das entrevistadas, $40 \%$ referiram ter concluído residência em Saúde da Família ou Saúde Coletiva. 
A formação dos recursos humanos precisa cada vez mais se articular com a organizaçáo do sistema de saúde, de modo a formar profissionais qualificados para atender as necessidades e demandas populacionais, de acordo com sua realidade demográfica e epidemiológica. A crescente discussão sobre essa temática retrata a desarticulaçáo entre políticas sociais, educacionais e prestação de serviços em Saúde (HADDAD et al., 2010).

Dentre as novas exigências de qualificação, voltadas para a realidade demográfica e epidemiológica do Brasil, destaca-se a necessidade de formação de profissionais e cidadãos críticos, comprometidos com a ética e a justiça social, aptos para atuarem em contextos de desigualdade social, compreendendo-a e intervindo adequadamente (DRUMMOND; RODRIGUES, 2004). Esse cenário de desigualdade é parte da realidade encontrada no cotidiano de trabalho dos profissionais inseridos nas equipes do NASF.

\section{Considerações finais}

A atenção à saúde muda em consonância com as necessidades e demandas da população e com sua demografia e epidemiologia, o que exige profissionais qualificados para o desempenho das novas açốes e aplicação de novas metodologias. Inseridos nas equipes NASF da cidade do Recife, os terapeutas ocupacionais, ainda que não formados especificamente para essa área, podem colocar em prática conhecimentos teóricos e/ou práticos adquiridos durante a graduação e a pós-graduação.

No entanto, constata-se que, para as entrevistadas, o Curso de Terapia Ocupacional tem priorizado o enfoque em algumas áreas de atuação, deixando a desejar nos ensinamentos a respeito da atenção primária em saúde, como a abordagem sobre as políticas de Saúde. Em contrapartida, as terapeutas ocupacionais têm buscado atualizar-se para oferecerem serviços de qualidade ao usuário, atendendo as novas demandas de um contexto de atenção à saúde também novo para essa profissional. É positivo destacar que as ferramentas próprias do trabalho no NASF também contribuem para a formaçáo, suprindo as lacunas do processo de educação formal.

Sendo assim, sugere-se que as instituições formadoras de recursos humanos para o serviço em Saúde adotem currículos inovadores que acompanhem as exigências do novo modelo de atenção interdisciplinar e integral.

Ao profissional de Saúde se requisita que esteja devidamente instrumentalizado para enfrentar as novas exigências do mercado de trabalho. Atualmente, na atenção básica, o cuidado ao paciente é calcado na utilização de tecnologia leve, nas relações interprofissionais, no acolhimento e produção de vínculos que conduzem a ação profissional ao encontro dos usuários e suas necessidades de saúde, exigindo domínio desses dispositivos assistenciais.

Vê-se que o papel do terapeuta ocupacional na equipe NASF do Recife está atrelado não só aos fundamentos (núcleo) da Terapia Ocupacional mas também aos papéis que são de atribuição comum às demais profissóes inseridas na atenção básica (campo).

Vale ressaltar que algumas limitaçóes metodológicas desse estudo abrem caminho para a realização de pesquisas sobre a temática, as quais possam compreender melhor a percepção desses profissionais em relação à sua assistência em saúde no território, dentro da equipe NASF. Os dados coletados poderão ajudar na direção a se tomar na organização do serviço e na formaçáo de recursos humanos para a Saúde.

\section{Referências}

AMBRÓSIO, S. C. et al. Atuação dos profissionais dos Núcleos de Apoio à Saúde da Família (Nasf), com enfoque ao trabalho do Nutricionista. 2009. $32 \mathrm{f}$. Monografia (Graduação em Nutrição)-Faculdade de Ciências da Saúde, Universidade Vale do Rio Doce, Governador Valadares, 2009. Disponível em: <http://www.pergamum.univale. br>. Acesso em: 15 maio 2011 .

ANDRADE, M. M. Como preparar trabalhos para cursos de pós-graduacão: noçôes práticas. 6. ed. São Paulo: Atlas, 2004.

ANDRADE, L. M. B. et al. Análise da implantação dos Núcleos de Apoio à Saúde da Família no interior de Santa Catarina. Saúde \& Transformação Social, Florianópolis, v. 3, n. 1, p. 18-31, jan. 2012. Disponível em: <http://pepsic.bvsalud.org/scielo.php?pid=S2178$70852012000100005 \&$ script $=$ sci_arttext $>$. Acesso em: 03 fev. 2013.

BALLARIN, M. L. G. S.; BLANES, L. S.; FERIGATO, S. H. Apoio matricial: um estudo sobre a perspectiva de profissionais da saúde mental. Interface: Comunicação, Saúde, Educação, Botucatu, v.16, n. 42, p. 767-778, 2012. http://dx.doi.org/10.1590/S1414-32832012000300014

BARBOSA, R. G. et al. Experiência da fisioterapia no Núcleo de Apoio à Saúde da Família em Governador Valadares, MG. Fisioterapia em Movimento, Curitiba, v. 23 , n. 2, p. 323-330, abr./jun. 2010. http://dx.doi. org/10.1590/S0103-51502010000200015

BEIRÃO, R. O. S.; ALVES, C. K. A. Terapia Ocupacional no SUS: refletindo sobre a normatização vigente. Cadernos de Terapia Ocupacional da UFSCar, São Carlos, v. 18, n 3, p. 231-246, set./dez. 2010. Disponível em: <http:// 
www.cadernosdeterapiaocupacional.ufscar.br/index. php/cadernos/article/viewFile/378/293>. Acesso em: 20 abr. 2011.

BEZERRA, R. S. et al. Arranjo matricial e o desafio da interdisciplinaridade na atenção básica: a experiência do Nasf em Camaragibe/PE. Divulgação em Saúde para Debate, Rio de Janeiro, v. 46, p. 51-59, maio 2010.

BONALUME, C. R. O paradigma da intersetorialidade nas políticas públicas de esporte e lazer. Licere, Belo Horizonte, v. 14, n. 1, p. 1-26, mar. 2011. Disponível em: <http:// www.anima.eefd.ufrj.br/licere/pdf/licereV14N01_ar1. pdf $>$. Acesso em: 20 maio 2011.

BRASIL. Conselho Nacional de Educação. Câmara de Educação Superior. Resolução CNE/CES 6, de 19 de fevereiro de 2002. Institui Diretrizes Curriculares Nacionais do Curso de Graduação em Terapia Ocupacional. Diário Oficial da República Federativa do Brasil, Brasília, 4 mar. 2002. Seção 1, p. 12. Disponível em: <http:// portal.mec.gov.br/cne/arquivos/pdf/CES062002.pdf>. Acesso em: 19 maio 2011.

BRASIL. Constituição da República Federativa do Brasil de 1988. Diário Oficial da República Federativa do Brasil, Brasília, 05 out. 1988. Seção 1. Disponível em: <http:// www.planalto.gov.br/ccivil_03/constituicao/constituicao. htm>. Acesso em: 13 jun. 2011.

BRASIL. Ministério da Saúde. Lei no 8.080, de 19 de setembro de 1990. Lei Orgânica da Saúde. Dispóe sobre as condiçóes para a promoçáo, proteção e recuperação da saúde, a organização e o funcionamento dos serviços correspondentes e dá outras providências. Diário Oficial da República Federativa do Brasil, Brasília, 20 set. 1990a. Seção 1. Disponível em: <http://portal.saude.gov.br/portal/ arquivos/pdf/lei8080.pdf>. Acesso em: 23 maio 2011.

BRASIL. Ministério da Saúde. Lei Federal no 8.142, de 28 de dezembro de 1990. Lei Orgânica da Saúde. Dispõe sobre a participação da comunidade na gestão do Sistema Único de Saúde (SUS) e sobre as transferências intergovernamentais de recursos financeiros na área da saúde e dá outras providências. Diário Oficial da República Federativa do Brasil, Brasilia, 29 dez. 1990b. Seção 1. Disponível em: <http://portal.saude.gov.br/portal/arquivos/ pdf/lei8080.pdf>. Acesso em: 23 maio 2011.

BRASIL. Ministério da Saúde. Secretaria Executiva. Núcleo Técnico da Política Nacional de Humanização. HumanizaSUS: Política Nacional de Humanização: A humanização como eixo norteador das práticas de atenção e gestão em todas as instâncias do SUS. Brasília: Ministério da Saúde: 2004a. (Série B. Textos Básicos de Saúde). Disponível em: <http://bvsms.saude.gov.br/ bvs/publicacoes/humanizasus_2004.pdf>. Acesso em: 23 nov. 2011.

BRASIL. Ministério da Saúde. Secretaria-Executiva. Núcleo Técnico da Política Nacional de Humanização. HumanizaSUS: equipe de referência e apoio matricial. Brasília: Ministério da Saúde, 2004b. (Série B. Textos Básicos de Saúde).
BRASIL. Ministério da Saúde. Portaria no 648/GM, de 28 de março de 2006. Aprova a Política Nacional de Atenção Básica, estabelecendo a revisão de diretrizes e normas para a organização da Atenção Básica para o Programa Saúde da Família (PSF) e o Programa Agentes Comunitários de Saúde (PACS). Diário Oficial da República Federativa do Brasil, Brasília, 29 mar. 2006. Seção 1. Disponível em: <http://bvsms.saude.gov.br/bvs/saudelegis/gm/2006/ prt0648_28_03_2006.html>. Acesso em: 13 jul. 2011.

BRASIL. Ministério da Saúde. Portaria GM no 154 , de 24 de janeiro de 2008. Cria os Núcleos de Apoio à Saúde da Familia - Nasf. Diário Oficial da República Federativa do Brasil, Brasília, 25 jan. 2008a. Seção 1. Disponível em: <http://www.saude.ba.gov.br/dab/arquivos/ portaria154.2008.pdf>. Acesso em: 23 maio 2011.

BRASIL. Ministério da Saúde. Secretaria de Gestão no Trabalho e da Educação na Saúde. Programa de Educação pelo Trabalho para a Saúde - PET-SAÚDE. Brasília: Ministério da Saúde, 2008b. Disponível em: <http://www.prosaude.org/noticias/prosaude-maio2009/ resumoPET-SAUDE-29-04-09.pdf>. Acesso em: 19 jun. 2012.

BRASIL. Ministério da Saúde. Secretaria de Atenção à Saúde. Departamento de Atenção Básica. Diretrizes do Nasf-Núcleo de Apoio à Saúde da Família. Brasília: Ministério da Saúde, 2009. (Série B. Textos Básicos de Saúde, Cadernos de Atenção Básica, n. 27). Disponível em: <http://bvsms.saude.gov.br/bvs/publicacoes/ caderno_atencao_basica_diretrizes_nasf.pdf >. Acesso em: 23 nov. 2010

BRASIL. Ministério da Saúde. Portaria no 2.488, de 21 de outubro de 2011. Aprova a Política Nacional de Atenção Básica, estabelecendo a revisão de diretrizes e normas para a organização da Atenção Básica, para a Estratégia Saúde da Família (ESF) e o Programa de Agentes Comunitários de Saúde (PACS). Diário Oficial da República Federativa do Brasil, Brasília, 22 out. 2011. Seção 1. Disponível em: <http://www.brasilsus.com.br/legislacoes/gm/110154-2488. html >. Acesso em: 1 nov. 2012.

BUSS, P. M.; PELLEGRINI FILHO, A. A saúde e seus determinantes sociais. Physis: Revista de Saúde Coletiva, Rio de Janeiro, v. 17, n. 1, p. 77-93, 2007. http://dx.doi. org/10.1590/S0103-73312007000100006

CAMPOS, G. W. S. Saúde pública e saúde coletiva: campo e núcleo de saberes e práticas. Ciência \& Saúde Coletiva, Rio de Janeiro, v. 5, n. 2, p. 219-230, 2000. http://dx.doi.org/10.1590/S1413-81232000000200002

CAMPOS, G. W. S.; AMARAL, M. A. A clínica ampliada e compartilhada, a gestão democrática e redes de atenção como referenciais teórico-operacionais para a reforma do hospital. Ciência \& Saúde Coletiva, Rio de Janeiro, v. 12, n. 4, p. 849-859, jul./ago. 2007. http://dx.doi.org/10.1590/ S1413-81232007000400007

CAMPOS, G. W. S.; GUERRERO, A. V. P. (Org.). Manual de Práticas da Atenção Básica: saúde ampliada e compartilhada. 2. ed. São Paulo: Editora Hucitec, 2010. 
CAMPOS, G. W. S.; DOMITTI, A. C. Apoio matricial e equipe de referência: uma metodologia para gestáo do trabalho interdisciplinar em saúde. Cadernos de Saúde Pública, Rio de Janeiro, 2007, v. 23, n. 2, p. 399-407. http://dx.doi.org/10.1590/S0102-311X2007000200016 COSTA, R. K. S.; MIRANDA, F. A. N. Formação profissional no SUS: oportunidades de mudanças na perspectiva da estratégia de saúde da família. Revista Trabalho, Educação e Saúde, Rio de Janeiro, v. 6, n. 3, p. 503-517, nov./fev. 2008-2009.

CUNHA, G. T.; CAMPOS, G. W. S. Apoio Matricial e Atenção Primária em Saúde. Saúde e Sociedade, São Paulo, v. 20, n. 4, p. 961-970, out./dez. 2011. http:// dx.doi.org/10.1590/S0104-12902011000400013

DECLARAÇÃO de Alma-Ata. In: CONFERÊNCIA INTERNACIONAL SOBRE CUIDADOS PRIMÁRIOS DE SAÚDE, 1978, Alma-Ata. Anais... Alma-Ata: OMS, OPAS, UNICEF, 1978. Disponível em: <http://www. opas.org.br/coletiva/uploadArq/Alma-Ata.pdf >. Acesso em: 23 nov. 2010.

DIMENSTEIN, M. et al. O apoio matricial em Unidades de Saúde da Família: experimentando inovaçóes em saúde mental. Saúde e Sociedade, São Paulo, v. 18, n. 1, p. 63-74, jan./mar. 2009. http://dx.doi.org/10.1590/ S0104-12902009000100007

DRUMMOND, A. F. Fundamentos da terapia ocupacional. In: CAVALCANTI, A.; GALVĀO, C. Terapia ocupacional: fundamentaçấo \& prática. Rio de Janeiro: Guanabara Koogan, 2007. p. 10-17. PMCid:PMC2474914.

DRUMMOND, A. F.; RODRIGUES, A. M. V. N. Os desafios da implantação de uma proposta de flexibilização curricular nos cursos de terapia ocupacional. Revista de Terapia Ocupacional da USP, São Paulo, v. 15, n. 3, p. 106-111, 2004. http://dx.doi.org/10.11606/issn.22386149.v15i3p106-111

FACUNDES, V. L. D. et al. Desafios na formaçáo do terapeuta ocupacional para atuação na atenção básica. In: SILVA, H. J. (Org.). Atenção básica em saúde na UFPE: experiências multidisciplinares. Recife: EdUFPE, 2010. p. 25-38.

FIGUEIREDO, M. D.; CAMPOS, R. O. Saúde Mental e Atenção Básica à Saúde: o apoio matricial na construção de uma rede multicêntrica. Saúde em Debate, Rio de Janeiro, v. 32, n. 78-80, p. 143-149. jan./dez. 2008.

HADDAD, A. E. et al. Formaçáo de profissionais de saúde no Brasil: uma análise no período de 1991 a 2008. Revista de Saúde Pública, São Paulo, v. 44, n. 3, p. 383-393, jun. 2010. http://dx.doi.org/10.1590/ S0034-89102010005000015

HAGEDORN, R. Terapia ocupacional: um esboço teórico e prático. In: HAGEDORN, R. Fundamentos da prática em terapia ocupacional. São Paulo: Dynamis Editorial, 1999. p. 13-19.

JARDIM, T. A. et al. A terapia ocupacional na Estratégia de Saúde da Família - evidências de um estudo de caso no município de São Paulo. Revista de Terapia Ocupacional da USP, São Paulo, v. 19, n. 3, p. 167-175, dez. 2008. http://dx.doi.org/10.11606/issn.2238-6149.v19i3p167-175 KELL, M. C. G.; SHIMIZU, H. E. Existe trabalho em equipe no Programa de Saúde da Família? Ciência \& Saúde Coletiva, Rio de Janeiro, v. 15, p. 1533-1541, 2010. Suplemento 1. http://dx.doi.org/10.1590/ S1413-81232010000700065

LOPES, R. E. et al. XI Encontro Nacional de Docentes de Terapia Ocupacional: refletindo sobre os processos de formaçáo acadêmica e profissional. Revista de Terapia Ocupacional da USP, São Paulo, v. 19, n. 3, p. 159-166, 2008. http://dx.doi.org/10.11606/issn.2238-6149. v19i3p159-166

MALTA, D. C. et al. A Política Nacional de Promoçáo da Saúde e a agenda da atividade física no contexto do SUS. Epidemiologia e Serviços de Saúde, Brasília, v. 18, n. 1, p. 79-86, mar. 2009. http://dx.doi.org/10.5123/ S1679-49742009000100008

MÂNGIA, E. F.; LANCMAN, S. Núcleos de apoio à saúde da família: integralidade e trabalho em equipe multiprofissional. Revista de Terapia Ocupacional da USP, São Paulo, v. 19, n. 2, p. i, 2008. http://dx.doi. org/10.11606/issn.2238-6149.v19i2pi-i

MATTHEWS, M. M.; TIPTON-BURTON, M. Contextos de tratamento. In: PEDRETTI, L. W.; EARLY, M. B. Terapia ocupacional. Capacidades práticas para as disfunçōes físicas. 5. ed. São Paulo: Roca, 2004. p. 31-40.

MOLINI-AVEJONAS, D. R.; MENDES, V. L. F.; DE LA HIGUERA AMATO, C. A. Fonoaudiologia e Núcleos de Apoio à Saúde da Família: conceitos e referências. Revista da Sociedade Brasileira de Fonoaudiologia, São Paulo, v. 15, n. 3, p. 465-474, 2010. http://dx.doi.org/10.1590/ S1516-80342010000300024

MENEZES, C. A. Implantação do Núcleo de Apoio ao Programa de Saúde da Familia (Nasf) em Olinda: Estudo de Caso. 2011. 68 f. Monografia (Especialização em Gestão de Sistemas e Serviço de Saúde)-Centro de Pesquisas Aggeu Magalhães, Fundação Oswaldo Cruz, Recife, 2011. NASCIMENTO, D. D. G.; OliVEIRA, M. A. C. Reflexôes sobre as competências profissionais para o processo de trabalho nos Núcleos de Apoio à Saúde da Família. O Mundo da Saúde, São Paulo, v. 34, n. 1, p. 92-96, 2010

OLIVER, F. C.; ALMEIDA, M. C. Reabilitação baseada na comunidade. In: CAVALCANTI, A.; GALVÃO, C. Terapia ocupacional: fundamentaçáo e prática. Rio de Janeiro: Guanabara Koogan, 2007. p. 125-130. PMCid:PMC2474914.

RECIFE. Rede de atençâo básica comemora um ano do Núcleo de Apoio à Saúde da Família. Disponível em: <http://www.recife.pe.gov.br/2011/06/13/ rede_de_atencao_basica_comemora_um_ano_do_ nucleo_de_apoio_a_saude_da_familia_177218.php>. Acesso em: 29 jun. 2011.

RECIFE. Secretaria Municipal de Saúde. Plano Municipal de Saúde 2010-2013. Recife: Secretaria Municipal de 
Saúde, 2010. Disponível em: <http://www.susrecife. com/2012/02/plano-municipal-de-saude-2010-2013. html>. Acesso em: 28 jan. 2013.

SILVA, I. Z. Q. J.; TRAD, L. A. B. O trabalho em equipe no PSF: investigando a articulação técnica e a interação entre os profissionais. Interface: Comunicação, Saúde, Educação, Botucatu, v. 9, n. 16, p. 25-38, set./fev. 2004-2005. http://dx.doi.org/10.1590/S1414-32832005000100003 SOARES, L. B. T. História da terapia ocupacional. In: CAVALCANTI, A.; GALVÃO, C. Terapia ocupacional: fundamentação \& prática. Rio de Janeiro: Guanabara Koogan, 2007. p. 3-9. PMCid:PMC2474914.

UNIVERSIDADE FEDERAL DE PERNAMBUCO - UFPE. Projeto Pedagógico do Curso de Terapia Ocupacional. Recife: UFPE, 2010. Aprovado pelo Colegiado de Curso de Terapia Ocupacional em 21 de junho de 2010.

VIEIRA, S. G. Perfil dos terapeutas ocupacionais em uma capital da Região Nordeste. 2010. 25 f. Monografia (Graduação em Terapia Ocupacional)-Universidade Federal de Pernambuco, Recife, 2010.

\section{Contribuição dos Autores}

Andréia Lima foi responsável pela coleta e análise de dados, redação e revisão do artigo. Ilka Falcão foi responsável pela orientação em todas as fases da pesquisa e participação na redação e revisão do artigo final.

\section{Notas}

${ }^{1}$ Este material é fruto de uma pesquisa desenvolvida em consonância com os procedimentos éticos vigentes e apresentada como Trabalho de Conclusão de Curso de Terapia Ocupacional da Universidade Federal de Pernambuco. 